\title{
PENERAPAN E-COMMERCE MENGGUNAKAN CMS WORDPRESS UNTUK MENINGKATKAN PENJUALAN PADA ONLINE SHOP FLANELIS
}

\author{
Aunul Fuad ${ }^{1)}$, Safitri Juanita ${ }^{2)}$ \\ ${ }^{1}$ Sistem Informasi, Fakultas Teknologi Informasi, Universitas Budi Luhur \\ 1,2 Jl. Raya Ciledug, Petukangan Utara, Kebayoran Lama, Jakarta Selatan 12260 \\ E-mail : fuadaunulfuad13@gmail.com ${ }^{1)}$, safitri.juanita@budiluhur.ac.id ${ }^{2}{ }^{2}$
}

\begin{abstract}
Abstrak
Online shop Flanelis merupakan salah satu penjualan online yang bergerak pada fashion wanita remaja hingga dewasa. Dari hasil observasi dan wawancara yang dilakukan, penulis menemukan permasalahan yang terjadi diantaranya kurang dari segi pemasaran dikarenakan online shop Flanelis baru menggunakan beberapa sosial media saja dalam menjual produk dan belum adanya laporan yang bisa dicetak melalui system sehingga pemilik online shop flanelis hanya menyimpan catatan penjualan berupa chat atau bukti transfer berbentuk foto yang tersimpan di whatsApp dan line. Tujuan penelitian ini adalah untuk meningkatkan penjualan online shop Flanelis dan dengan dibuatkannya website berbasis E-Commerce ini pelaku usaha dapat mencetak laporan dengan akurat. Adapun metode penelitian yang digunakan seperti wawancara, observasi, analisa dokumen dan studi literature, dan mengimplementasi E-Commerce dengan menggunakan CMS (content management system) WordPress. Kesimpulan dari penelitian ini adalah dengan dibuatkannya E-Commerce membantu online shop Flanelis untuk membuat pemasaran yang lebih luas lagi, mencetak laporan dengan cepat juga akurat dan menyediakan website sendiri, untuk mengoptimalkan website ini harus dilakukan pelatihan kepada admin yang akan mengelola, maintenance secara berkala untuk meningkatkan effesiensi dan efektifitas juga diperlukannya promosi sebagai salah satu strategi pemasaran pada website Flanelis.
\end{abstract}

Kata kunci: E-Commerce, Meningkatkan Penjualan, CMS, Fashion

\section{PENDAHULUAN}

E-commerce adalah elektronik commerce merupakan istilah umum untuk proses pembelian dan penjualan yang didukung oleh cara-cara yang elektronik [1]. Pada era digital saat ini kita dimudahkan dalam melakukan bisnis yang tidak perlu mengeluarkan banyak modal untuk menyewa toko atau memakai jasa banyak karyawan karena sudah banyak media online yang menyediakan wadah untuk berjualan.

Flanelis adalah online shop yang menjual tas backpack, slingbag, handbag, card holder dan straps bag import dengan harga yang terjangkau. Online shop Flanelis berdiri pada tahun 2015. Sistem penjualan yang digunakan oleh Flanelis itu sendiri menggunakan instagram, line dan whatsApp dengan id instagram @Flanelis dan belum memiliki E-commerce sehingga penjualan masih belum maksimal juga dikhawatirkan kalah bersaing dalam penjualan. Customer selama ini jika ingin membeli produk dari Flanelis menggunakan official account line dengan id @Flanelis dan menggunakan nomor whatsapp 0895-1778-5862 sebagai media interaksi dan transaksi. Dengan menggunakan fasilitas sosial media sebagai sarana penjualan maka ruang lingkup atau jangkauan maupun promosi masih kurang luas karena hanya mengandalkan followers dari instagram dan pengikut dari line. Catatan penjualan berupa bukti transfer yang tersimpan pada line dan whatsApp sehingga pemilik harus screenshot untuk menyimpan bukti penjualan dalam bentuk gambar. Solusi yang diajukan untuk mengatasi masalah dari Flanelis untuk mengembangkan bisnis penjualannya yaitu E-commerce.

Pada latar belakang di atas terdapat beberapa permasalahan seperti belum maksimalnya media pemasaran pada online shop Flanelis karena baru menggunakan beberapa media sosial saja, tidak adanya laporan yang bisa dicetak dari hasil penjualan sehingga pencatatan penjualan masih berupa chat yang tersimpan di whatsApp dan line dan tidak adanya laporan yang bisa dicetak dari sisa stock barang yang masih tersedia setiap bulannya.

Adapun tujuan dan manfaat pada penulisan ini yaitu dengan dibuatkannya website berbasis $E$ commerce penjualan online yang menyediakan fasilitas chart atau keranjang pembelian, yang otomatis tersimpan di database sehingga menghasilkan laporan yang informatif dan akurat, membantu mempromosikan produk dari online shop Flanelis agar lebih dikenal masyarakat luas dan dibuatkan website berbasis E-commerce, agar pelaku usaha dapat mencetak laporan penjualan, laporan pembayaran, laporan pengiriman, laporan pemesanan, laporan stock dan laporan best seller. 
Ruang lingkup permasalahan pada penulisan ini yaitu pada website berbasis E-commerce ini terdapat proses pembelian, proses pembayaran, proses pengiriman dan proses laporan dan juga membahas tentang langkah-langkah pada pembuatan website E-commerce sampai dengan pembuatan laporan.

\section{STUDI LITERATUR}

Dalam hal ini penulis mencari referensi dari penelitian sebelumnya, referensi yang digunakan penulis untuk menyelesaikan penelitian ini yaitu dari [2] dengan judul, Perancangan E-Commerce Batik Pada Batik Banten. Penelitian ini membahas tentang toko fisik yang menjual batik di daerah Banten, dalam hal tersebut peneliti menemukan beberapa permasalahan seperti penjualan yang belum maksimal karena hanya mengandalkan pelanggan yang datang ke toko, pelaku usaha belum menggunakan sistem informasi dalam penjualan dan dalam pembuatan laporan yang kurang efektif sehinggan peneliti ingin mengimplementasikan sistem informasi electronic commerce ( $E$ Commerce) agar pelaku usaha dapat meningkatkan penjualan dan mempermudah pelaku usaha dalam pembuatan laporan yang lebih akurat dan mudah. Salah satu metodologi pengembangan sistem yang digunakan peneliti yaitu dengan metode waterfall. Dapat disimpulkan dengan dibuatkannya sistem informasi berbasis E-Commeerce dapat memudahkan pelanggan dalam pembelian dan mengetahui informasi produk, memperluas pemasaran dan juga memudahkan dalam pembuatan laporan.

Adapun referensi dari penelitian [3] dengan judul, Sistem Informasi Penjualan Kaos Berbasis Web Pada Distro Sickness Berbasis E-Commerce. Dari penelitian yang dilakukan terdapat berbagai macam masalah pada distro sickness yaitu belum menggunakan sistem informasi, kurangnya dari segi pemasaran, kesulitan dalam mengetahui produkproduk terbaru dari distro sickness bagi para pelanggan sehingga harus mengunjungi distro terlebih dahulu agar tau produk-produk terbarunya. Dari masalah tersebut peneliti membuatkan website penjualan berbasis E-Commerce untuk solusi dari permasalahan yang ada pada distro sickness. Pada penelitian ini menggunakan beberapa metode pengumpulan data seperti metode observasi, metode wawancara, dan juga studi pustaka. Adapun rancangan sistem dan program usulan, untuk pelanggan yaitu terdapan halaman/tampilan, login, produk kategori, riwayat pemesanan dan keranjang belanja sedangkan untuk admin dapat mengelola data barang, data pemesanan, dan data pelanggan. Dapat disimpulkan melalui website penjualan ini dapat memberikan informasi produk-produk yang terbaru dan masih tersedia, mempermudah pelanggan dalam pemesanan dan juga jangkauan pasar yang lebih luas agar dikenal masyarakat.

\section{METODE PENELITIAN}

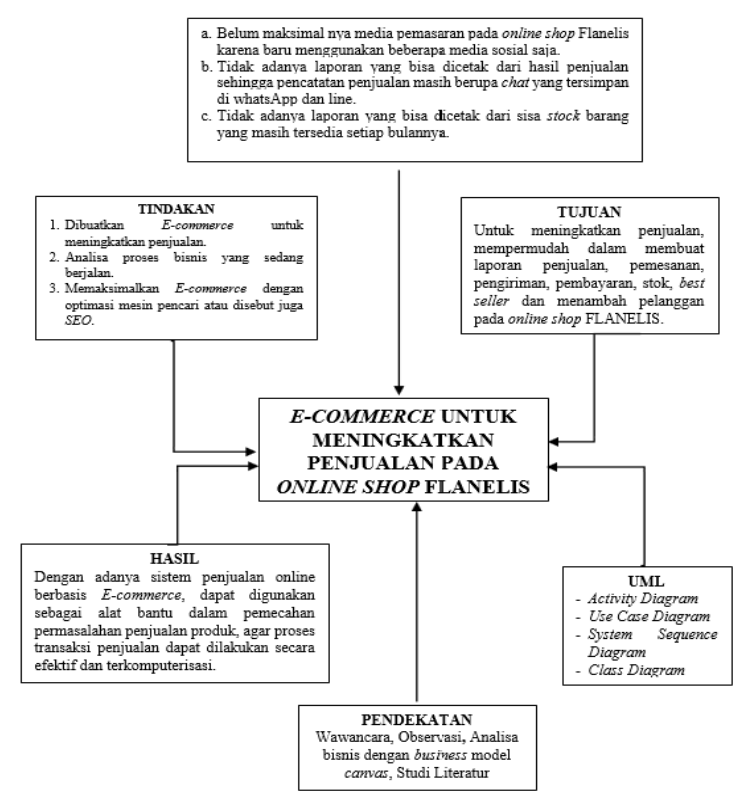

Gambar 1. Kerangka Pemikiran

Pada gambar 1. merupakan teknik pengumpulan data yang berisikan masalah, tindakan, tujuan, hasil, uml yang digunakan dan pendekatan kepada pemilik online shop. Hal ini dapat bersangkutan dengan bagaimana cara mengumpulkan data, pada sumbernya, dan alat yang dipergunakan. Untuk sumber data yang dikumpulkan dan digunakan pada penelitian, berupa :

a. Wawancara

Langkah ini bertujuan untuk mempelajari dan menganalisa pada sistem yang sudah berjalan serta menerima data informasi langsung dari Nuri Rositania sebagai narasumber, dengan cara tanya jawab tentang alur aktifitas usahanya dan meminta dokumen yang dimiliki. Wawancara dilaksanakan dengan memberi pertanyaan yang sebelumnya sudah disediakan untuk pemilik usaha agar dapat memberikan informasi yang sangat penting.

b. Observasi

Observasi pada metode pengumpulan data dengan melakukan pengamatan kepada objek penelitan secara langsung dan dapat menarik kesimpulan untuk semua kegiatan oleh objek tersebut. Observasi ini dilaksanakan untuk online shop Flanelis yang beralamat di jl.buntu RT.7/RW.10, Palmerah, Kota Jakarta Barat.

c. Analisa Dokumen 
Menganalisis dokumen yang terdapat pada online shop Flanelis dengan contoh dokumen yang sudah diberikan yaitu screenshot transaksi penjualan dari online shop Flanelis sebelum tanggal 11maret2019.

\section{d. Studi Literatur}

Studi literatur ini diterapkan agar mendapatkan referensi dari penelitian sebelumnya menyangkut pembahasan yang sama dengan pembahasan yang akan ditulis pada online shop Flanelis, dengan menggunakan cara membaca juga mamahami pada literatur dari beberapa referensi jurnal, buku, artikel ataupun bahan perpustakaan yang berkaitan pada masalah yang sedang diteliti.

e. Implementasi

Untuk mendesain website pada online shop Flanelis, seperti memilih tema, memasukkan plugin yang diperlukan, memposting produk dan dibuat semenarik mungkin agar customer mengunjungi website flanelis.com dan berminat membeli produk dari online shop Flanelis.

\section{HASIL DAN PEMBAHASAN}

\subsection{BMC (Business Model Canvas)}

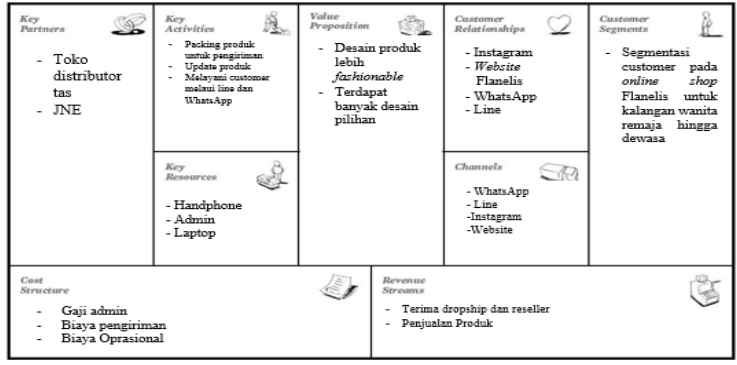

Gambar 2. BMC (Business Model Canvas)

Pada gambar 2. adalah Business Model Canvas yang sudah penulis buat dan digunakan pada online shop Flanelis.

Berikut ini ialah penjelasan tentang komponenkomponen yang terdapat didalam Business Model Canvas, yaitu:

a. Key Partners

Yang tercantum pada key partners itu ialah pihak yang terkait seperti distributor-distributor tas yang berkerja sama untuk mensuplai berbagai macam kebutuhan dari tempat usaha online shop Flanelis.

b. Key Activities

Suatu usaha yang memakai sumber-sumber yang dimiliki untuk diproduksi menjadi produk yang akan dijual oleh online sheop Flanelis.

c. Key Resources

Sumber utama mengenai suatu usaha dengan memproduksi nilai untuk kelancaran aktivitas bisnis pada sebuah perusahaan.

d. Value Proposition
Merupakan inti pada nilai yang telah disediakan dari online shop Flanelis untuk pelanggan.

e. Customer Relationship

Media yang telah dipakai oleh online shop Flanelis agar dimengerti bagaimana cara memasarkan produk dan juga berinteraksi pada pelanggan.

f. Channels

Berisi tentang sarana yang digunakan oleh online shop Flanelis untuk sebuah produk bisa tersampaikan kepada pelanggan.

g. Customer Segments

Tentang tahap penentuan siapa yang akan menjadi target penjualan untuk memasarkan produk.

h. Cost Structure

Merupakan struktur biaya apa yang dikeluarkan pada online shop Flanelis pada sebuah produk.

i. Revenue Stream

Isi dari Revenue Stream yaitu usaha online shop Flanelis dari segi apa saja penghasilan juga keuntungannya.

\subsection{Activity Diagram}

Activity diagram ialah alur dari aktifitas yang dilakukan pada proses bisnis [4]. Berikut ini adalah activity diagram yang dibuat penulis pada penelitian:

a. Proses Pendaftaran

Pada gambar 3. ialah proses pendaftaran yang dilakukan pelanggan agar dapat login pada website Flanelis dengan cara mengunjungi web terlebih dahulu.

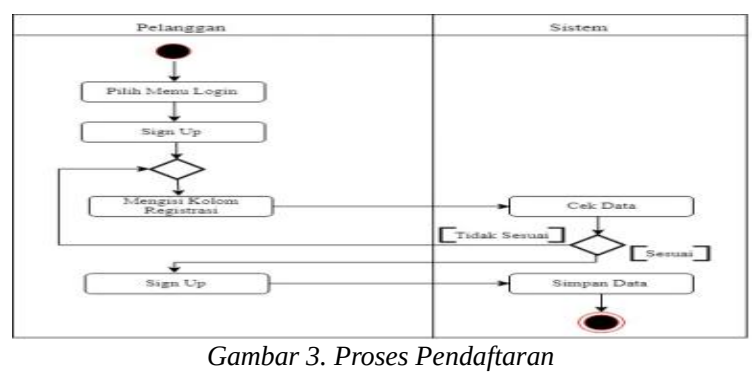

b. Proses Pemesanan Barang

Pada gambar 4. ialah proses pemesanan barang yang merupakan aktivitas pelanggan ketika ingin memesan barang di website Flanelis.

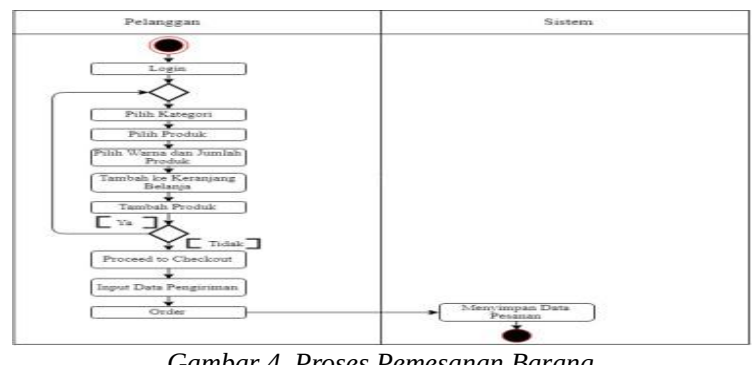

Gambar 4. Proses Pemesanan Barang 
c. Proses Konfirmasi Pembayaran

Pada gambar 5. Ialah proses konfirmasi pembayaran yang dilakukan jika pelanggan sudah selesai memilih barang yang ingin dibeli kemudian mengisi form confirm payment yang tersedia di menu.

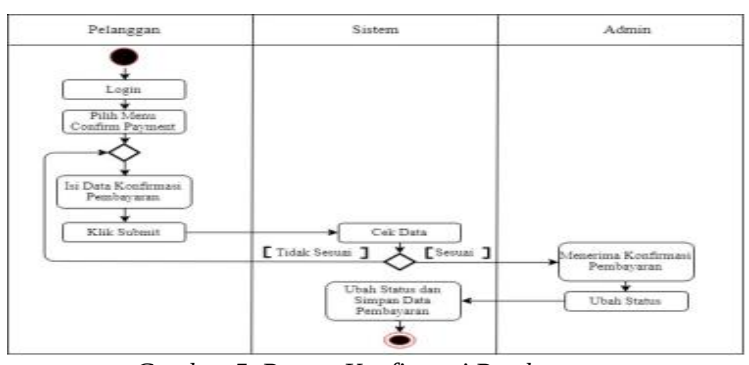

Gambar 5. Proses Konfirmasi Pembayaran

\section{d. Proses Input Resi}

Pada gambar 6. Admin login untuk menginput resi setelah pelanggan melakukan pembayaran yang sudah valid.

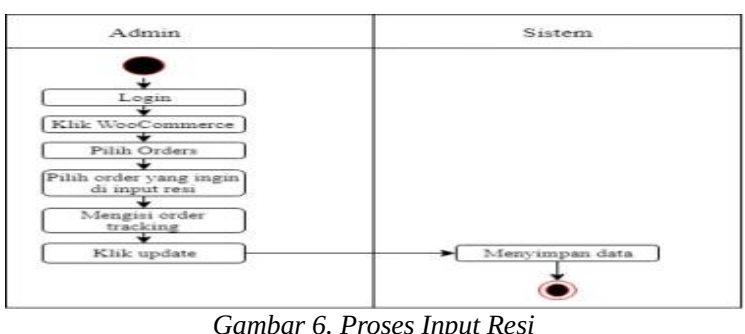

e. Proses Tambah Kategori

Pada gambar 7. merupakan aktivitas admin ketika ingin menambahkan kategori pada website Flanelis yang sebelumnya sudah login terlebih dahulu.

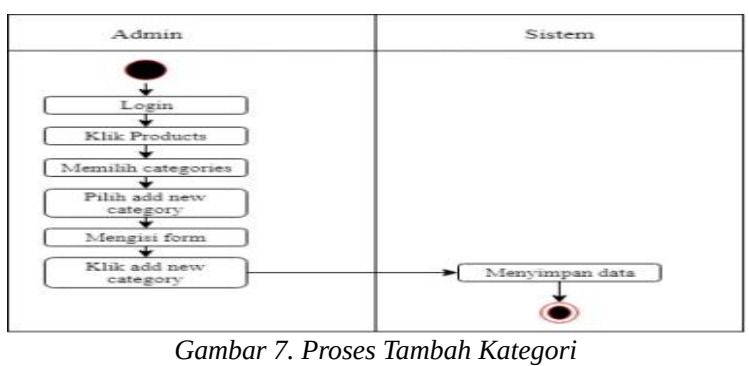

f. Proses Tambah Barang

Pada gambar 8. merupakan aktivitas admin ketika menambahkan barang atau produk yang akan dijual di website Flanelis.

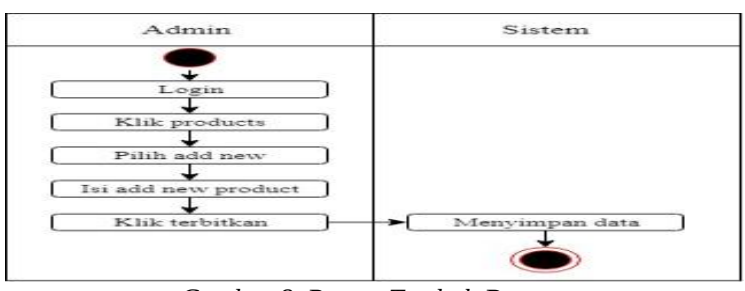

Gambar 8. Proses Tambah Barang g. Proses Pembuatan Laporan

Pada gambar 9. Merupakan laporan yang dibuat untuk diserahkan kepada pemilik usaha dan sudah dicetak oleh admin.

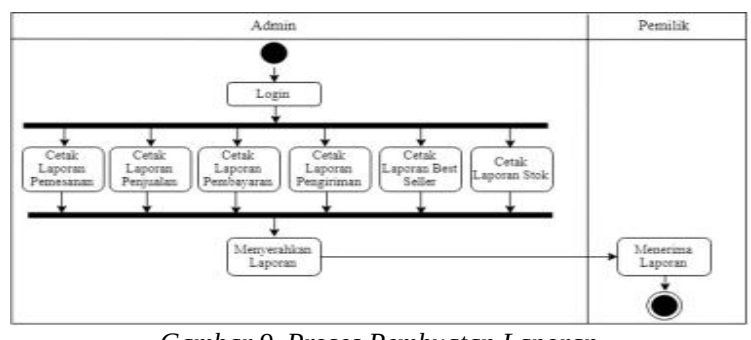

Gambar 9. Proses Pembuatan Laporan

\subsection{Use Case Diagram}

Use case diagram menggambaran fungsi yang terdapat dari sistem [5]. Berikut ini ialah use case diagram yang telah dibuat:

a. Use Case Diagram Master

Pada gambar 10. Pelanggan sudah dalam kondisi login dan dapat mengakses menu di website flanelis.com. Admin bisa menambahkan produk dan kategori.

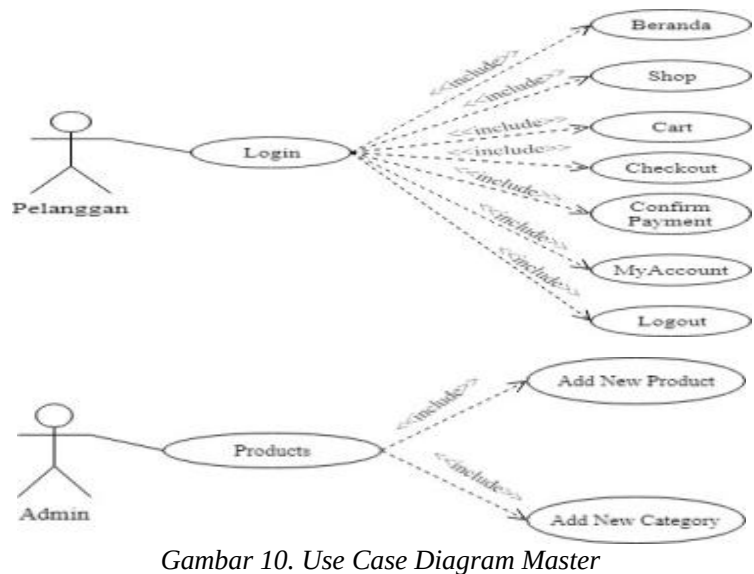

b. Use Case Diagram Transaksi

Pada gambar 11. Pelanggan dapat mengentry pesanan dan juga melakukan pembayaran kemudian admin akan memeriksa dan mengkonfirmasi.

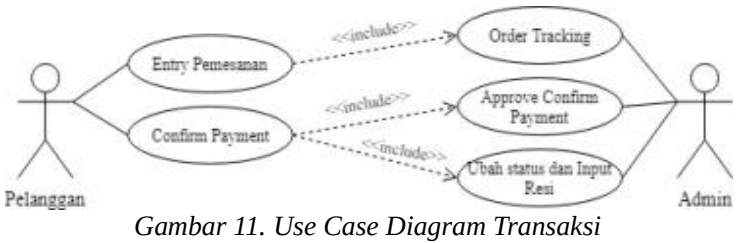

c. Use Case Diagram Laporan

Pada gambar 12. Admin dapat mencetak laporan pengiriman, laporan pembayaran, laporan stok barang, laporan penjualan, laporan best seller dan rekapitulasi yang akan diserahkan kepada pemilik usaha. 


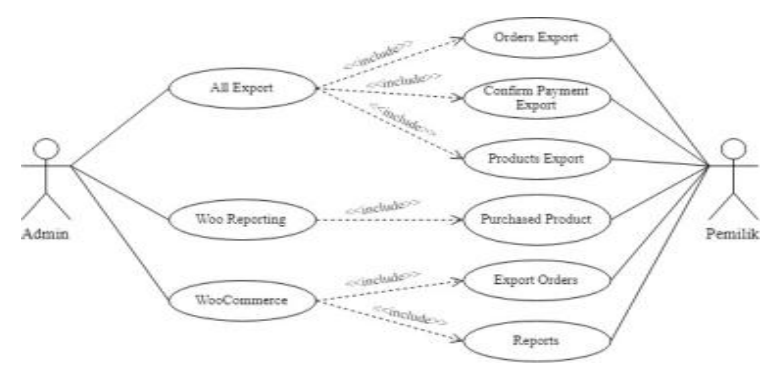

Gambar 12. Use Case Diagram Laporan

\subsection{Class Diagram}

Class diagram ialah salah satu spesifikasi jika di instansi akan mendapatkan suatu obyek dan merupakan inti pada pengembangan juga gambaran berorientasi obyek [6].

Pada gambar 13. Adalah class diagram yang terdapat di website Flanellis.

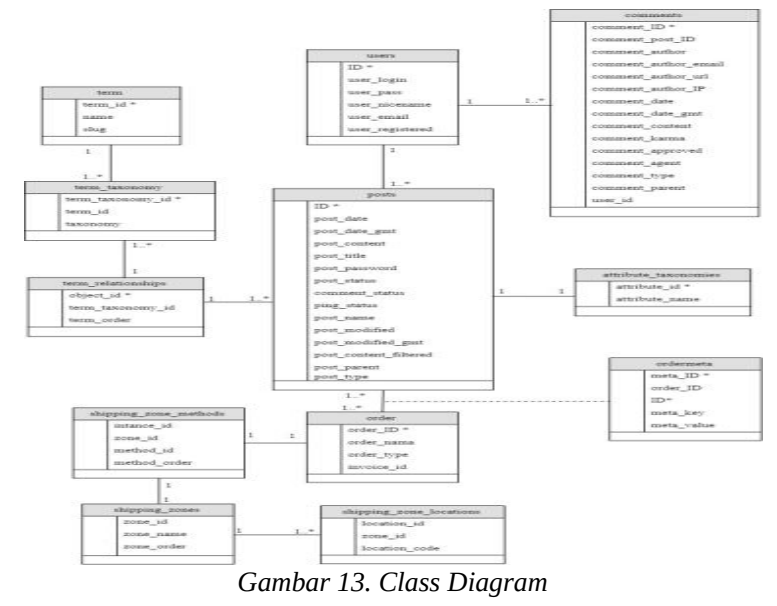

\subsection{Implementasi Program}

Berikut tampilan layar yang telah dibuat dalam penelitian:

\section{a. Orders}

Pada gambar 14. Merupakan menu orders dari admin yang fungsinya untuk mengetahui status orderan yang masuk jika barang sudah sampai kepada pelanggan status nya akan menjadi completed.

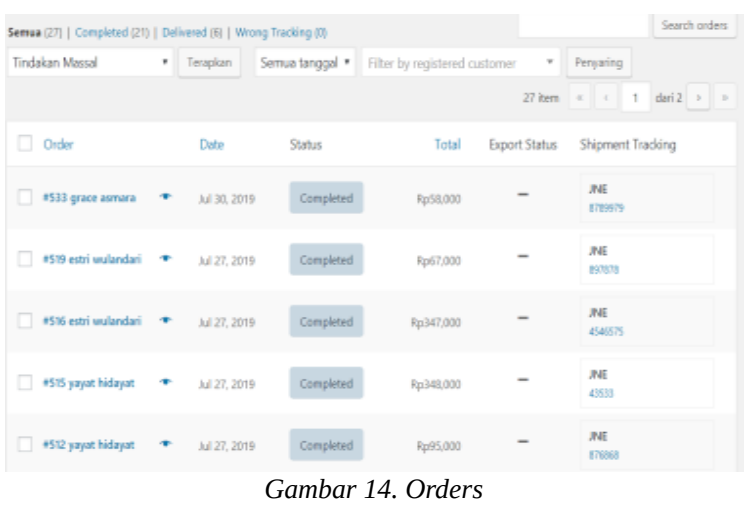

b. Konfirmasi Pembayaran

Pada gambar 15. Merupakan konfirmasi pembayaran atau approve confirm payment, ini dilakukan setelah admin mengecek bukti pembayaran yang sudah valid. Pada menu confirm payment terdapat slip/bukti transfer, nama pelanggan, nomer orderan, nama bank, jumlah transfer, tanggal transfer, nomer telpon pelanggan, tanggal konfirmasi pembayaran dan status konfirmasi pembayaran.

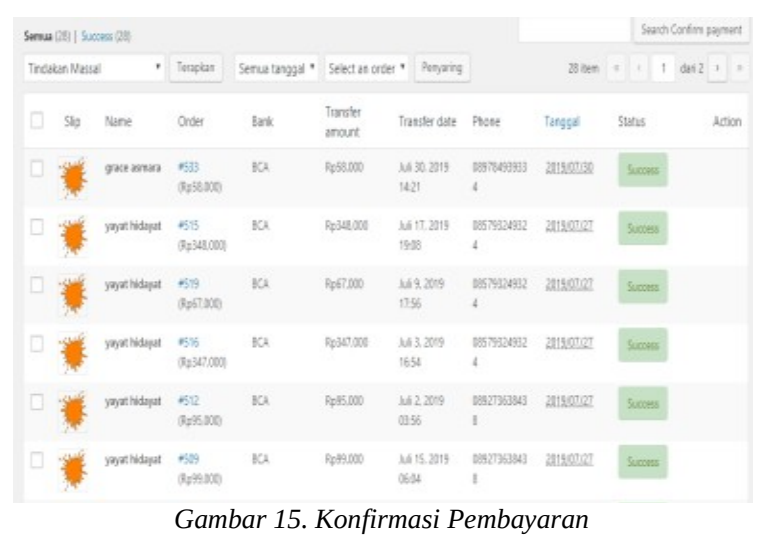

c. Laporan Penjualan

Pada gambar 16. Merupakan laporan dalam satu bulan terakhir yang bisa dicetak oleh admin, dengan pendapatan kotornya Rp3.221.000, rata-rata penjualan harian Rp103.903, pendapatan bersih Rp3.009.000, rata-rata penjualan bersih harian Rp97.065, orders placed 23, items purchased 28, tidak ada refund, dengan biaya pengiriman keseluruhan dalam satu bulan terakhir Rp212.000.

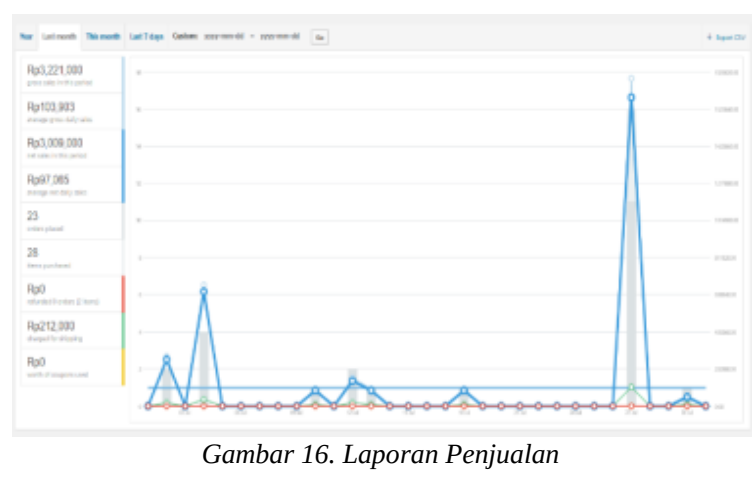

d. Laporan Best Seller

Pada gambar 17. Merupakan best seller yang bisa dicetak oleh admin dan akan memberikannya pada pemilik usaha. Pada laporan best seller yang berbentuk bulat, memiliki warna berbeda, terdapat nama produk, warna produk, dan memiliki persentasi itu ialah produk yang terjual, dapat dilihat warna merah mendominasi dengan presentasi 20.77\% terdapat nama produk yaitu "Jual Slingbag dengan 3 pilihan warna” pilihan warna produk brown itu ialah produk terlaris atau best seller nya. 


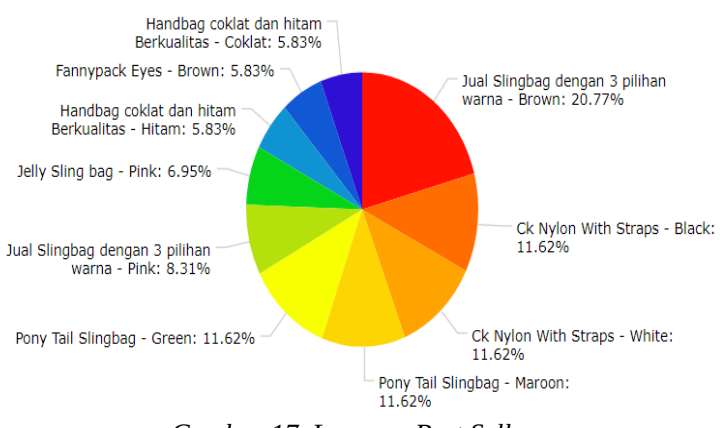

Gambar 17. Laporan Best Seller

\subsection{Struktur Tampilan Menu}

a. Front end Pelanggan

Pada gambar 18. adalah tampilan website pelanggan sebelum login. Terdapat menu beranda, shop, cart, checkout, confirm payment dan login.

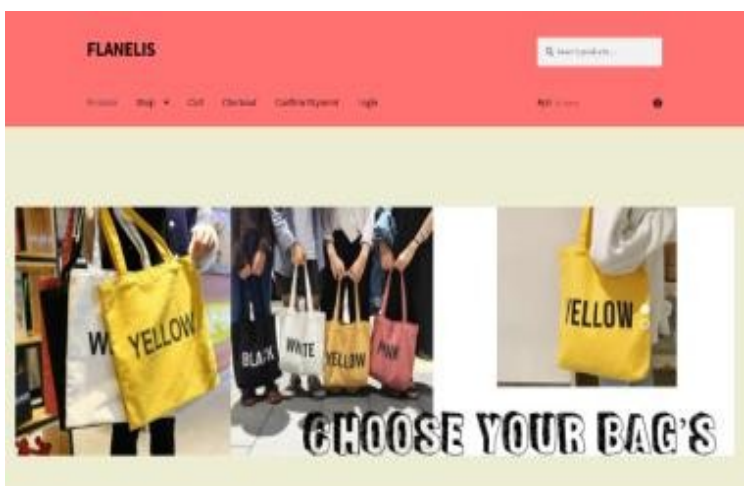

Gambar 18. Front end Pelanggan

b. Back end Pelanggan

Pada gambar 19. Merupakan tampilan menu back end pelanggan untuk melihat orderan yang sudah valid atau bisa disebut juga history pembelian pelanggan.

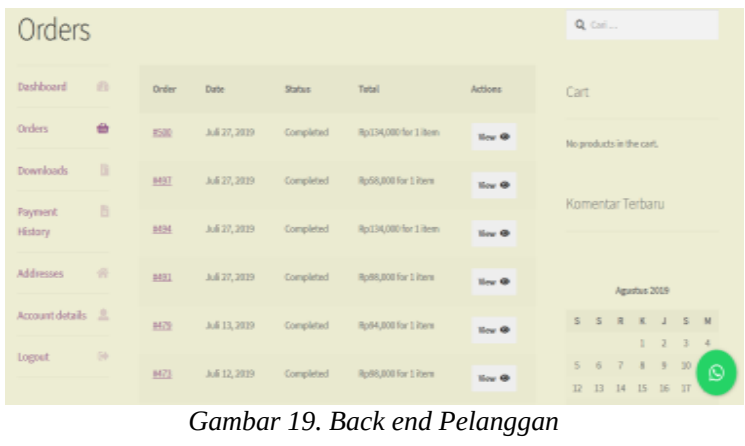

c. Back end Admin

Pada gambar 20. Merupakan menu yang ada pada admin, dalam mengelola website untuk penerapan E-Commerce yang paling sering digunakan oleh admin yaitu seperti, menu WooCommerce di dalamnya terdapat sub menu orders yang berguna untuk melihat orderan masuk sampai dengan orderan completed atau transaksi sudah selesai, kemudian ada menu Products di dalamnya terdapat sub menu add new yang berguna untuk menambahkan produk baru dan categories untuk menambahkan kategori baru, dan menu Confirm Payment yang berguna untuk mengkonfirmasi pembayaran jika data yang ada sudah valid dan sesuai. Adapun menu lainnya seperti Woo Reporting yang berguna untuk membuat laporan best seller dan juga menu lainnya untuk pendukung dalam pengelolaan website.

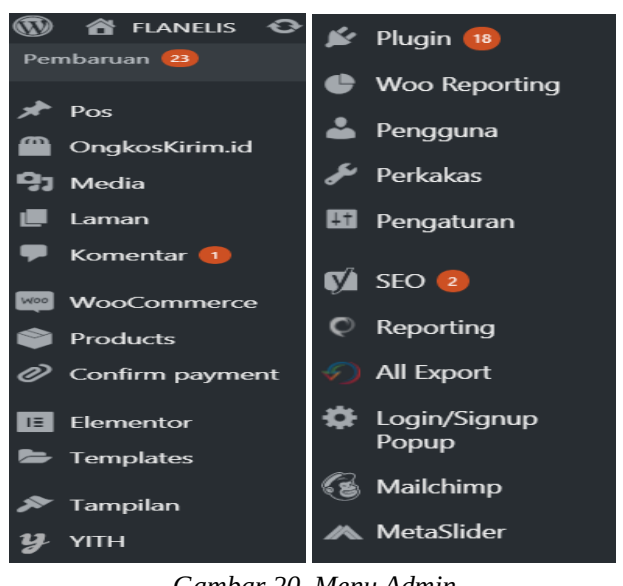

Gambar 20. Menu Admin

\subsection{SEO (Search Engine Optimization)}

Search Engine Optimization (SEO) ialah suatu proses yang mengenakan prinsip-prinsip dasar pencarian pada suatu mesin pencari dengan tujuan mendapatkan dan menambahkan nilai indeks peringkat yang lebih tinggi dalam satu halaman website ataupun juga bisa digunakan untuk meningkatkan jumlah akses kunjungan [7]. Berikut ini adalah langkah-langkah penerapan SEO pada website www.flanelis.com :

a. Pilih Produk

Pada gambar 21. Ketika memilih produk yang akan diterapkan SEO. Sebelumnya kita pasang plugin Yoast SEO, lalu pilih menu products pada toko online shop Flanelis kemudian ke menu all products, dan pilih produk yang akan dipasangkan SEO.

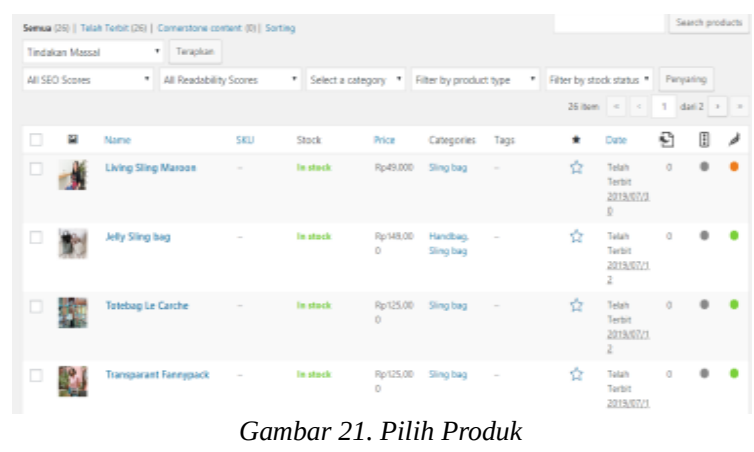


b. Isi Kolom Pada Focus Keyphrase

Pada gambar 22. Merupakan gambaran Focus Keyphrase. Pertama harus mengisi kolom dibawah kalimat focus keyphrase sebagai kata kunci produk yang akan digunakan, kemudian edit snippet untuk mengisi SEO title, slug, dan meta description. Untuk SEO title dan meta description diharuskan membuat kalimat sampai parameter berwarna hijau agar mudah terbaca oleh google.

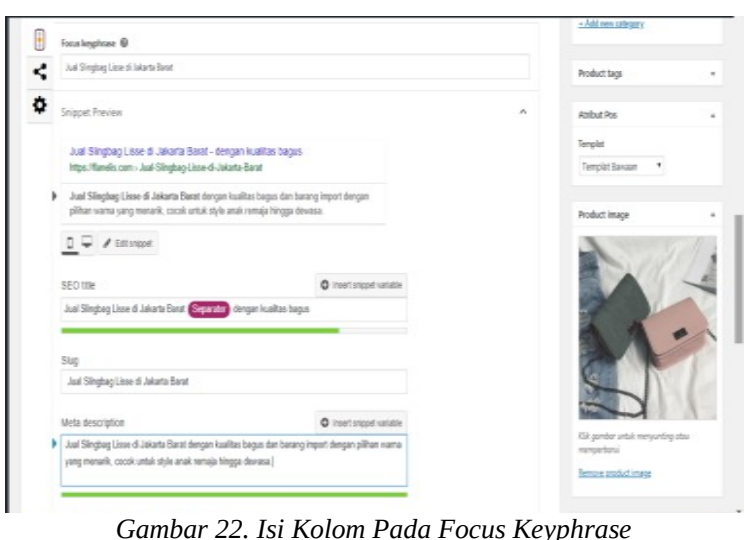

c. Gambar Produk

Pada gambar 23. Merupakan gambaran produk nya. Isi judul dan teks alt ketika ingin mengisi product image bisa juga disamakan dengan kata kunci yang sudah dibuat.

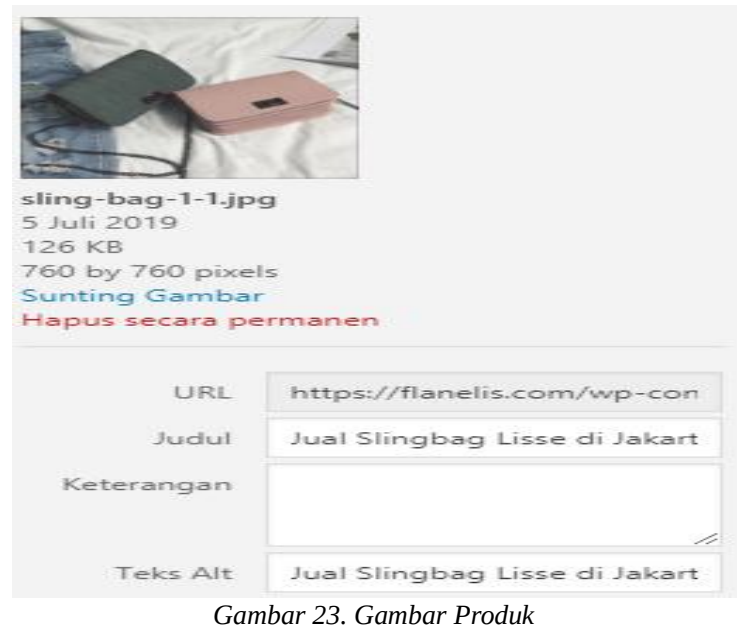

d. Inspeksi $U R L$

Pada gambar 24. Merupakan inspeksi URL. Periksa URL produk yang sudah dipakaikan SEO dengan cara membuka Google Search Console disitu login dengan email dan daftarkan alamat website, setelah itu copy link produk yang akan di inspeksi dan paste di periksa semua URL kemudian indeksi link selama dua menit.

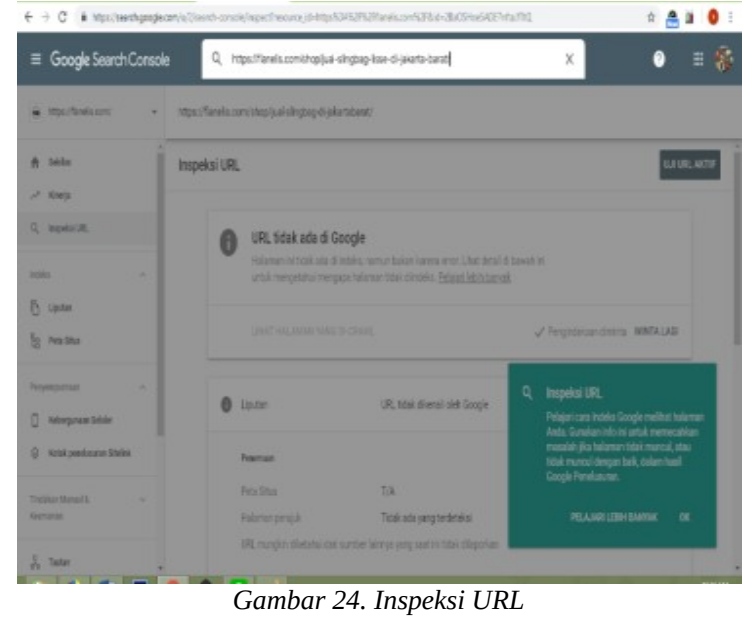

e. Hasil Pencarian

Pada gambar 25. Merupakan hasil dari pencarian di google. Lihat di pencarian google dengan kata kunci yang sudah digunakan, jika tidak ada dihalaman pertama cari di halaman kedua dan seterusnya, dari beberapa produk Flanelis dengan kata kunci ” Jual Sling bag Lisse di Jakarta Barat” ada pada halaman pertama, pencarian dilakukan pada tanggal 23 juni2019.

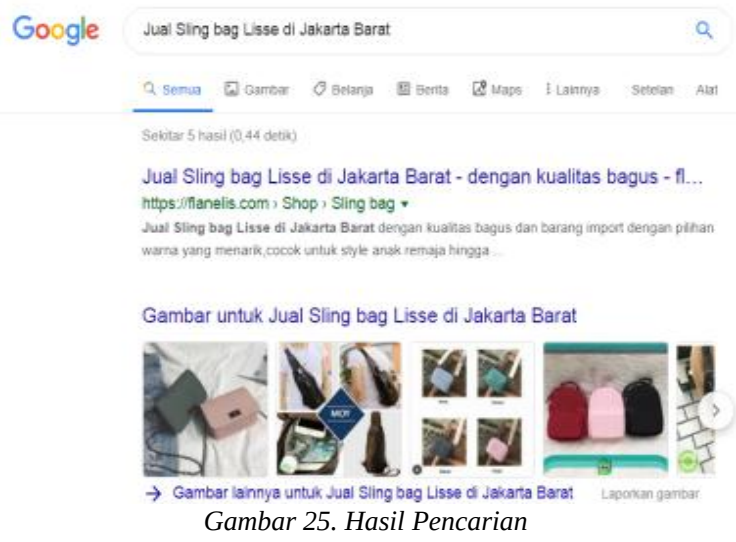

\section{KESIMPULAN}

Pada penelitian kali ini, penulis dapat menarik kesimpulan, yaitu:

a. Dengan dibuatkannya website berbasis Ecommerce pada online shop Flanelis jangkauan penjualan akan lebih luas dan tidak bergantung pada sosial media saja.

b. Dengan dibuatkannya website berbasis Ecommerce pada online shop Flanelis laporan stock bisa dicetak setiap bulannya yang memudahkan pemilik online shop dalam mengetahui produk yang masih tersedia.

c. Memudahkan pemilik online shop untuk mencetak hasil penjualan setiap bulannya. 
Saran yang diberikan:

a. Diperlukannya maintenance secara berkala untuk meningkatkan effesiensi dan efektifitas pada website Flanelis.

b. Diperlukannya promosi seperti potongan harga dan lain-lain pada event tertentu untuk menarik pembeli.

c. Diperlukannya model produk yang tidak terlalu pasaran agar membedakan produk penjualan website Flanelis dengan website lainnya.

d. Pengecekan dalam menambahkan produk agar tidak salah input ataupun salah informasi penjualan terhadap pembeli.

e. Pelatihan kepada admin yang akan mengelola website.

\section{DAFTAR PUSTAKA}

[1] Prasetyo \& Widodo, “Anteseden Kepercayaan Pengguna Pada Penawaran E-Commerce dan Konsekuensinya Terhadap Niat Beli,” E-Proceeding of Management, vol.4, pp. 1429-1436, 2017.

[2] Irma \& Suryani, "Perancangan E-commerce Batik Pada Batik Banten,” Teknik Informatika, vol.2, pp. 66-81, 2018

[3] Nugraha \& Octasia, "Sistem Informasi Penjualan Kaos Berbasis WEB Pada Distro Sickness Berbasis E-commerce,” SNIPTEK, vol.3, pp. 299-302, 2016.

[4] Prasetyo, "Rancangan Bangun Sistem Informasi Sekolah Tinggi Ilmu Ekonomi Rahmanyah Kabupaten Musi Banyuasin Berbasis Website," Informatika, vol.1, pp. 19-30, 2015.

[5] Irma \& Suryani, "Perancangan E-commerce Batik Pada Batik Banten,” Teknik Informatika, vol.2, pp. 66-81, 2018.

[6] Handoko \& dkk “ Pembuatan Website Pada UPT Pusat Kesehatan Masyarakat Desa Kalak,” Evolusi, vol.4, pp. 83-90, 2016.

[7] Halilintar \& Dony, "Implementasi SEO ( Search Engine Optimization ) Pada Website AGC ( Auto Generated Content ) Untuk Meningkatkan SERP ( Search Engine Result Page ),” Teknologi Informasi, vol.3, 13-18, 2018. 